Review

\title{
Smart Retrofit Solutions of Buildings toward a Low Carbon World
}

\author{
${ }^{1}$ Erdem Cuce and ${ }^{2}$ Pinar Mert Cuce \\ ${ }^{I}$ Department of Mechanical Engineering, Faculty of Engineering, \\ University of Bayburt, Dede Korkut Campus, 69000 Bayburt, Turkey \\ ${ }^{2}$ Department of Energy Systems Engineering, Faculty of Engineering, \\ Recep Tayyip Erdogan University, Fener Campus, 53100 Rize, Turkey
}

Article history

Received: 14-07-2018

Revised: 30-07-2018

Accepted: 28-08-2018

Corresponding Author:

Erdem Cuce

Department of Mechanical

Engineering, Faculty of

Engineering, University of

Bayburt, Dede Korkut Campus,

69000 Bayburt, Turkey

Email: erdemcuce@gmail.com

\begin{abstract}
In this short communication, energy-efficient, eco-friendly and low-cost solutions for existing buildings are considered in a holistic manner toward low/zero carbon building concept of near future. Buildings are still responsible for about $40 \%$ of total primary energy consumption in the world, hence decisive measures need to be taken promptly due to growing significance of environmental issues driven by fossil fuel based energy use. Smart solutions addressed within the scope of this research aim at analyzing the energy consumption behaviour of a typical building from building envelope to the appliances utilised, then propose key technologies for urgent mitigation of energy use and drastic reduction of greenhouse gas emissions. For the external walls, aerogel and vacuum insulation panel based thermal superinsulation solutions are recommended owing to the superior thermal resistance ability of such materials $(\lambda<0.01 \mathrm{~W} / \mathrm{mK}$ for current commercial products). For glazed areas, aerogel glazing, vacuum glazing, solar pond glazing, PV glazing, Transparent Insulation Material (TIM) glazing and Phase Change Material (PCM) glazing concepts are introduced. About $60 \%$ of total heat losses from building fabric is attributed to window, which proves the significance of energy-efficient solutions on fenestration products. Depending on environmental and regional conditions, solar, wind and biomass oriented hybrid solutions can be considered for clean energy generation. Current payback period of such systems is below five years, which is promising. Especially thermally resistive PV glazing systems integrated with $\mathrm{TiO}_{2}$ nano coating are capable of producing more than $100 \mathrm{~W}$ from per $\mathrm{m}^{2} 28$ of cell area with $100 \% \mathrm{UV}$ light blockage and self-cleaning feature. Polycarbonate based counter flow waste heat recovery systems are ideal for ventilation purposes with an average COP of about 3.5. For general heating and cooling purposes, air or ground source heat pump systems are found to be favourable for temperate and continental climatic conditions, respectively. Average COP of these systems is found to be greater than 3 in most cases, which is attractive. LED lighting systems are highly energy-efficient and cost-effective compared to the alternatives in market.
\end{abstract}

Keywords: Building Retrofit, Energy Efficiency, Low-Cost Restoration, Low-Carbon Economy, COP

\section{Introduction}

Buildings are responsible for about $40 \%$ of total world energy consumption (Cuce and Riffat, 2016). Recent reports of International Energy Agency (IEA) indicate that domestic sector plays a dramatic role on global energy use and carbon emissions (Cuce, 2016a). This can be explained with the poor thermal insulation characteristics of existing building materials (Cuce, 2014) and insufficient efficiency figures of current Heating, Ventilation and Air-Conditioning (HVAC) systems in market (Cuce, 2015). Especially in recent 
years, HVAC oriented energy consumption shows a rising trend as a consequence of technological developments and demand to enhanced thermal comfort conditions (Cuce and Cuce, 2017). Conventional building elements, out of date HVAC systems and inefficient home appliances considerably affect the overall building energy performance, energy consumption figures and carbon emissions (Besir and Cuce, 2018). Airtightness is also of vital importance in terms of heating and cooling demand and recent works reveal that existing building stocks are not airtight enough (Cuce, 2017a).

When a typical building envelope is considered, overall heat transfer coefficients (U-value) of main building elements provide a brief understanding about the level of heat loss across the building fabric (Cuce and Riffat, 2015a). Recent works indicate that the overall Uvalues of external walls, grounds, roofs and windows are $0.30,0.25,0.16$ and $2.00 \mathrm{~W} / \mathrm{m}^{2} \mathrm{~K}$, respectively. It is unequivocal to say that low/zero carbon building standards seem impossible to be reached through the conventional building materials as the limit values of thermal insulation performance are almost reached (Cuce and Cuce, 2016a). The case for the windows is much more complicated since the latest standards foresee a Uvalue below $1.20 \mathrm{~W} / \mathrm{m}^{2} \mathrm{~K}$, which requires drastic innovations in fenestration products (Cuce, 2018). Regarding the external walls and roofs, there is a consensus among scientists that air, as a thermal insulator, already reaches its limit. Therefore, air based conventional insulation materials such as glass wool and rock wool are not expected to be considered on building envelopes in the near future (Cuce et al., 2014a).

Clean energy generation technologies for buildings, notably Photovoltaic Thermal (PV/T) collectors (Cuce et al., 2018), their concentration applications (Daneshazarian et al., 2017) and hybrid solutions with wind and biomass (Daneshazarian et al., 2018) are in the centre of interest owing to their favourable energy production features and environmental aspects. Building-integrated PV and PV/T technologies are also attractive because of their multifunctional benefits (Cuce and Cuce, 2013a) such as electricity generation, thermal energy production, ventilation, sound insulation, etc. (Cuce and Cuce, 2013b). However, constructional and operational optimisation of the said systems is still a challenge that needs to be resolved.

Energy management is as much important as energy generation and in this 68 respect, for the efficient utilisation of energy in buildings, additional measures need to be taken as underlined by researchers in literature. At this point, waste heat/energy recovery technologies are of vital importance since there is a great potential of enhancing the overall building energy performance figures through heat recovery (Cuce et al., 2016). However, the buildings of today are poor in terms of waste heat recovery since the social awareness about the technology and its reliability is inadequate in most regions.

Regarding heating and cooling demand, it can be asserted that conventional air or ground source heat pump systems are considered as the latest technology in terms of cost effectiveness (Ding et al., 2015). However, the improvements on the COP values of such systems are limited as a consequence of several reasons. In most cases, inappropriate refrigerants are utilised in these systems with non-optimised structural and operational parameters, which notably affect the overall performance. Power outputs of the systems are usually determined without a quantitative analysis yielding to insufficient energy inputs or longer payback periods. The scenario is much more dramatic for the buildings which are still based on fossil fuels. The aforesaid systems usually provide poor thermodynamic performance figures and cause serious environmental matters as reported by many researchers in literature (Riffat and Cuce, 2012). On the other hand, heating and cooling systems using electricity are also not cost-effective for domestic sector even in developed countries (Cuce et al., 2014b).

Current building stocks in the world are still dependent on traditional lighting appliances like incandescent lamps, which play a noticeable role in total building energy consumption. In recent years, there are some attempts like transforming lighting devices to energy efficient white light producers. However, cost is still a challenge for these systems especially in the developing part of the world. Therefore, additional solutions are required on the fields of cost reduction, lifetime and lighting efficiency of the said systems as well as developing novel technologies (Cuce et al., 2015a).

The goal of this research is to provide smart retrofit solutions for buildings toward a low carbon world. The technologies cover state-of-the-art developments in the building systems and include cost-effective, energyefficient and eco-friendly solutions to mitigate building oriented energy use and carbon emissions. Each single technology is scientifically proved and passed from social acceptance surveys as all the data is derived from the on-site projects.

\section{Smart Technologies for Buildings}

\section{Solutions for External Walls}

Aerogel and vacuum insulation panel can be considered as the most appropriate thermal superinsulation solutions for the external walls of existing buildings and new-built structures (Moretti et al., 2017). Although cost of these materials is still remarkably higher than that of conventional insulation materials, there is a noticeable progress achieved over the last two decades in cost reduction, thermal and acoustic features (Cuce and Cuce, 2016b). Aerogel is addressed 
as the lightest insulation material in the world and its translucent structure makes it special for alternative applications like in glazing structures (Cuce et al., 2014c). On the other hand, vacuum insulation panels are usually utilised internally in domestic sector between sheets. Besides cost, the low strength is an outstanding handicap for this technology. Aerogel and vacuum insulation panel are illustrated in Fig. 1.

Cuce et al. (2014c) conduct several in-situ tests to evaluate the thermal insulation performance and costeffectiveness of aerogel retrofit for a typical 1930s house in the UK. At the pre retrofit case, the test house is observed to show poor thermal insulation behaviour especially due to dominant thermal bridging effects on building fabric. One of the rooms in the test house is internally retrofitted with $20 \mathrm{~mm}$ thick aerogel blanket. The external view of the test house and the retrofit details are shown in Fig. 2.

At the post-retrofit case, it is proved that internal aerogel restoration resolves the thermal bridging effects in the test house as shown in Fig. 3. On the other hand, aerogel retrofit is observed to mitigate $90 \%$ of heat losses from external walls. Besides, slimmer construction details are achieved through aerogel retrofit, typically about $70 \%$ less than glass wool and up to $50 \%$ less than polyurethane.

Today, the cost of aerogel is about 10 times greater than traditional insulation materials such as glass wool and rock wool, however the unit $\mathrm{m}^{3}$ price of aerogel is predicted to reduce below $£ 500.00$ by 2050 owing to potential developments in materials science. Regarding the vacuum insulation panels, there are also noticeable advancements which can be seen from Fig. 4. An office building in Munich is entirely retrofitted by vacuum insulation panels and the retrofitting is evaluated in terms of thermal insulation and cost-effectiveness (Pool, 2009). The results reveal that vacuum insulation panels provide superior thermal insulation feature by eliminating the thermal bridging effects on the building fabric. Cost is somewhat a challenge especially when compared to the conventional insulation materials, but notable cost reductions are estimated in the near future. However, even if air diffusion and moisture penetration into the core somehow could be resolved, the rigid structure and the perforation risk still stand as major drawbacks for this technology as reported in recent works (Kalnæs and Jelle, 2014).

\section{Solutions for Windows}

Windows are still the poorest building elements in terms of thermal resistance (Oleskowicz-Popiel and Sobczak, 2014). Cuce and Riffat (2015b) present a comprehensive research about novel glazing technologies toward low/zero carbon building standards. Novel glazing technologies have a wide range of types such as multilayer glazing, suspended films, vacuum glazing, low-emittance coatings, smart glazing, PV glazing, aerogel glazing, PCM glazing, solar pond glazing, gas filled glazing, self-cleaning glazing, reversible glazing and ventilated glazing. Among the available technologies, especially vacuum glazing, aerogel glazing, solar pond glazing, PV glazing and their hybrid applications are in the centre of interest owing to the multifunctional benefits of these fenestration products.

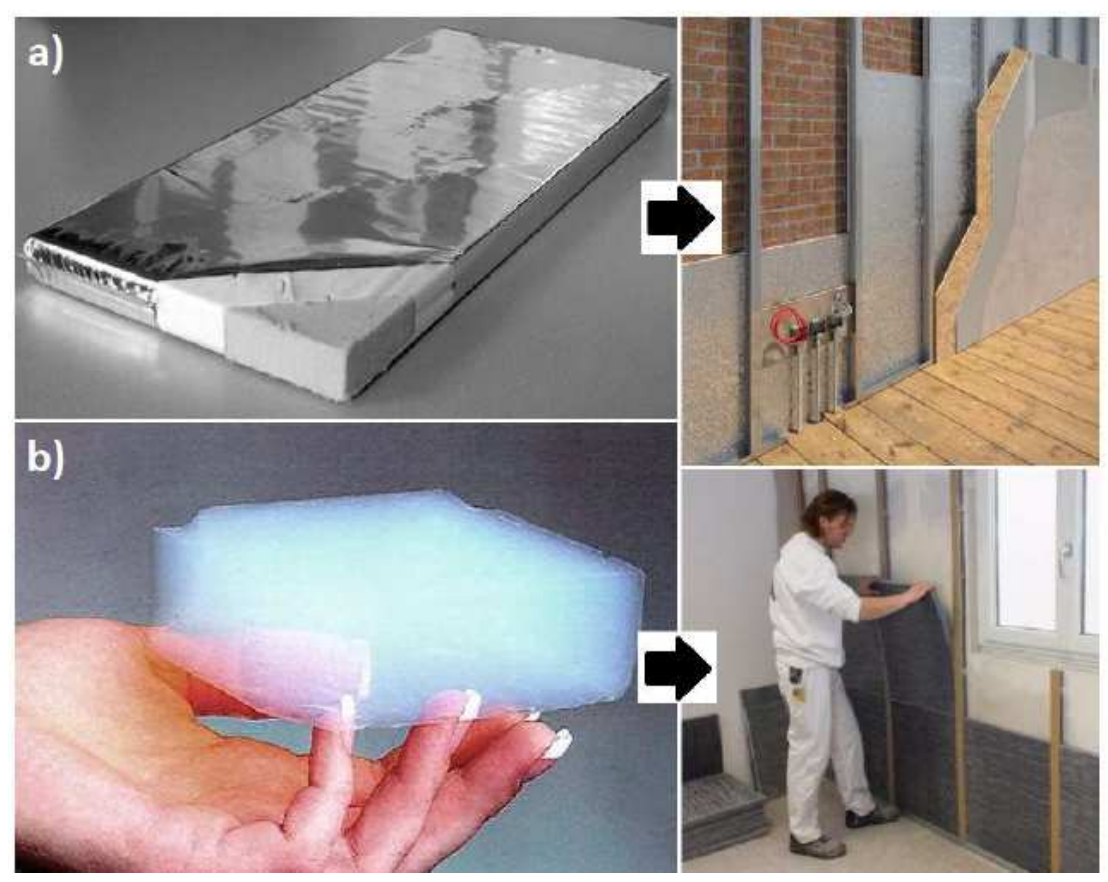

Fig. 1: Thermal superinsulation solutions for external walls: (a) Vacuum insulation panel and (b) aerogel with the retrofit details 

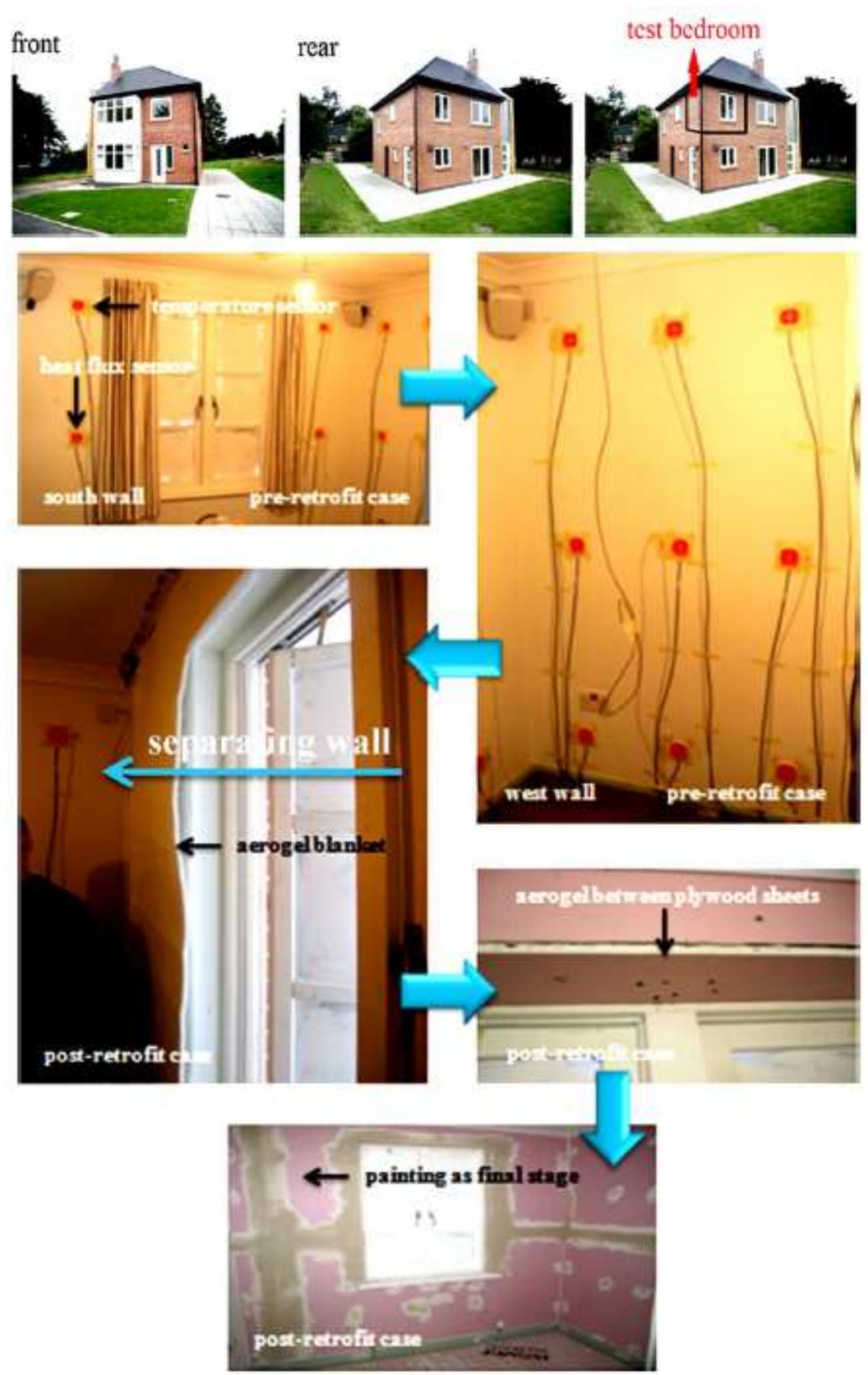

Fig. 2: Aerogel retrofit to a typical 1930s house in the UK (Cuce et al., 2014c)
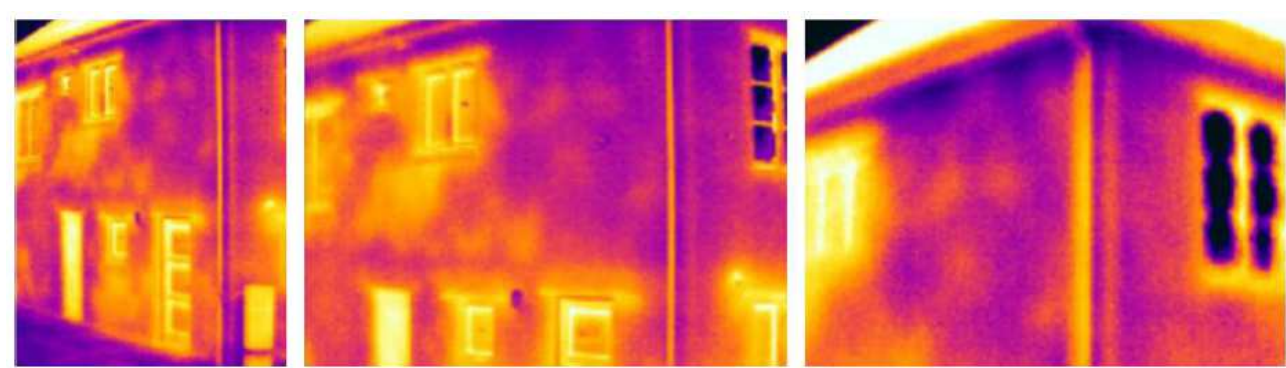

Fig. 3: Internal aerogel retrofit as a solution to thermal bridging effects (Cuce et al., 2014) 


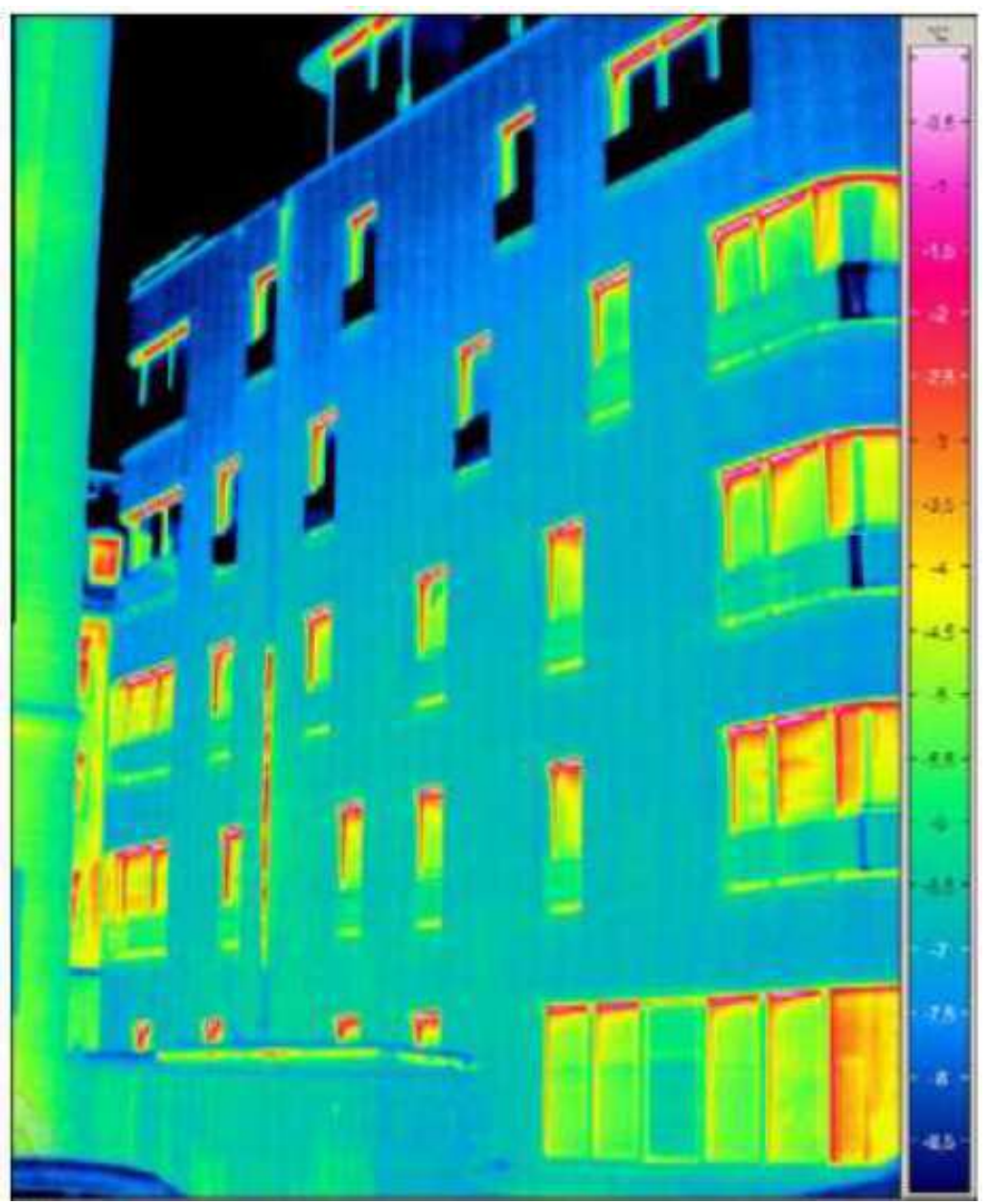

Fig. 4: Vacuum insulation panel retrofit to an office building in Munich (Kalnæs and Jelle, 2014)

PV glazing integrated with the phenomenon of multilayer glazing concept provides several advantages for building sector and there is a certain number of commercial products which are already available in market like heat insulation solar glass (Young et al., 2015). Heat insulation solar glass is investigated in terms of several aspects such as thermal insulation (Cuce et al., 2015b), power generation (Cuce et al., 2016a), optical features (Cuce et al., 2016b) and thermal comfort (Cuce et al., 2015c). Performance assessment tests of heat insulation solar glass are illustrated in Fig. 5. According to the results achieved, it can be easily asserted that heat insulation solar glass in an ideal clean energy generating building material with additional benefits such as thermal insulation and self-cleaning. The concept is capable of producing about $90 \mathrm{~W}$ electricity from per $\mathrm{m}^{2}$ and has a U-value of $1.10 \mathrm{~W} / \mathrm{m}^{2} \mathrm{~K}$, which is promising (Cuce, 2016b). $\mathrm{TiO}_{2}$ nano coating on the surface of amorphous silicon PV cell prevents the module area from dust and other contaminants, which yields to better electrical power outputs compared to conventional PV glazing systems (Cuce and Riffat, 2017).

It is clearly illustrated in Fig. 6 that U-value of heat insulation solar glass is capable of meeting the low carbon building standards whereas conventional glazing products are inadequate in terms of thermal resistance (Cuce et al., 2015b). Vacuum tube window is another novel glazing technology that can be considered for high thermally resistive building envelopes (Cuce and Cuce, 2016c). Experimental and numerical analyses conducted by Cuce $(2017 \mathrm{~b})$ reveal that $\mathrm{U}$-value of a vacuum tube window with a tube diameter of $60 \mathrm{~mm}$ is below 0.40 $\mathrm{W} / \mathrm{m}^{2} \mathrm{~K}$, which is very attractive. The sample developed and the numerical results are depicted in Fig. 7.

Vacuum glazing is also promising especially when support pillars are replaced with aerogel. Cuce and Riffat (2015c) conduct a numerical research for a commercial PV glazing product and they notify that the U-value, which is reported as $1.20 \mathrm{~W} / \mathrm{m}^{2} \mathrm{~K}$ by the manufacturer, can be reduced to $0.67 \mathrm{~W} / \mathrm{m}^{2} \mathrm{~K}$ via the aerogel replacement of support pillars. 


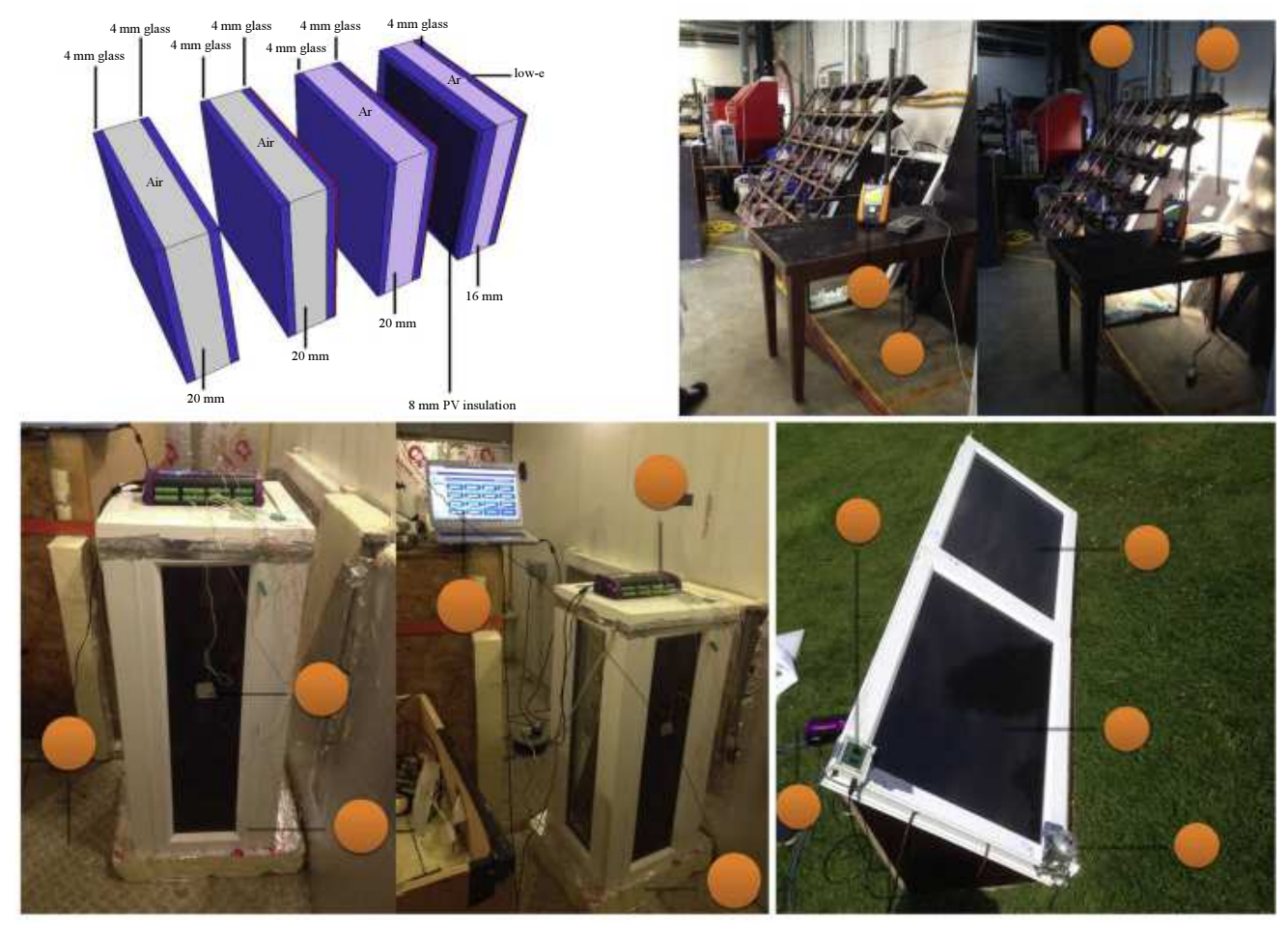

Fig. 5: Thermal insulation and power generation tests of heat insulation solar glass (Cuce et al., 2015c)
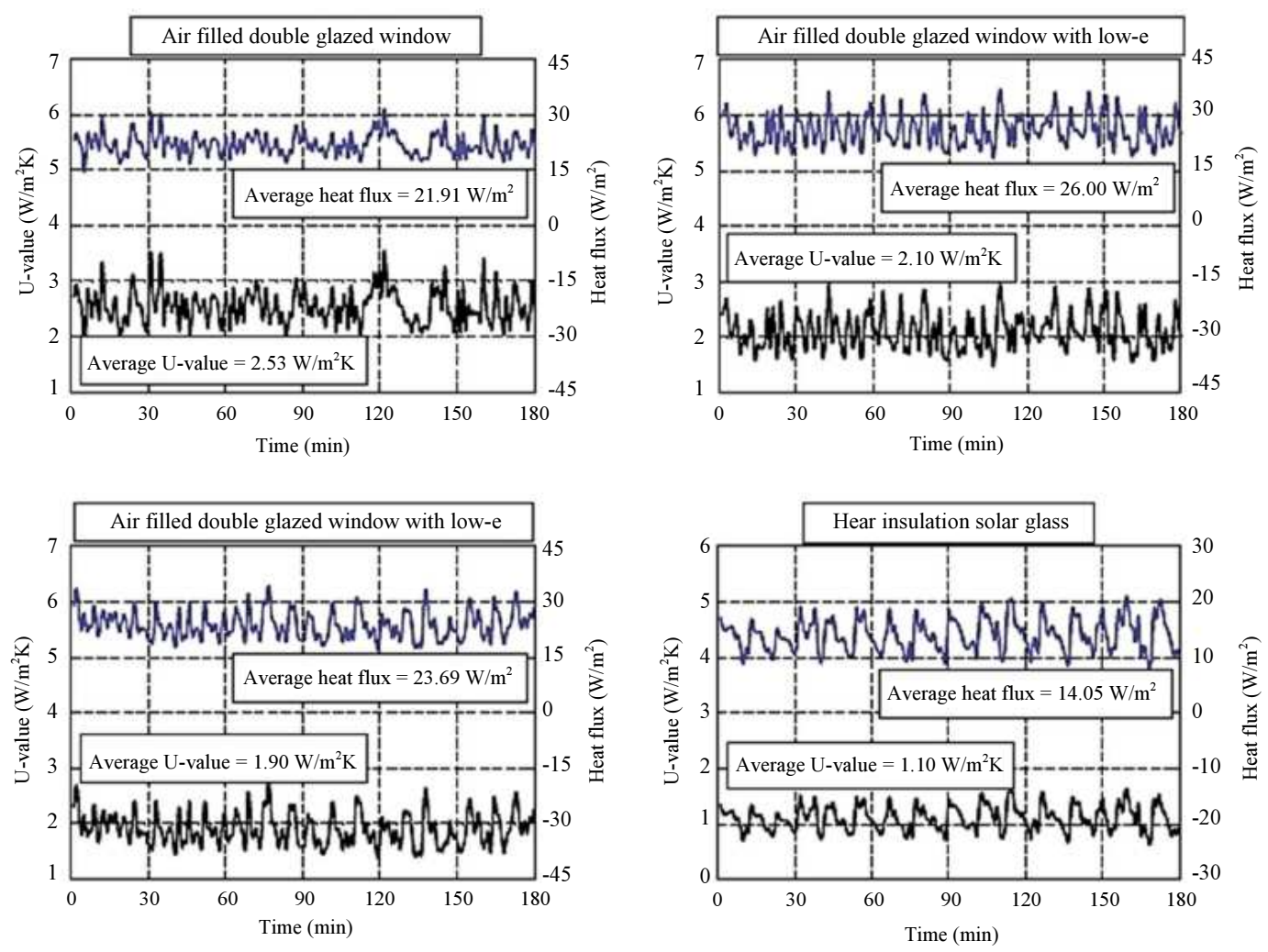

Fig. 6: U-value of heat insulation solar glass and conventional glazing products (Cuce et al., 2015b) 

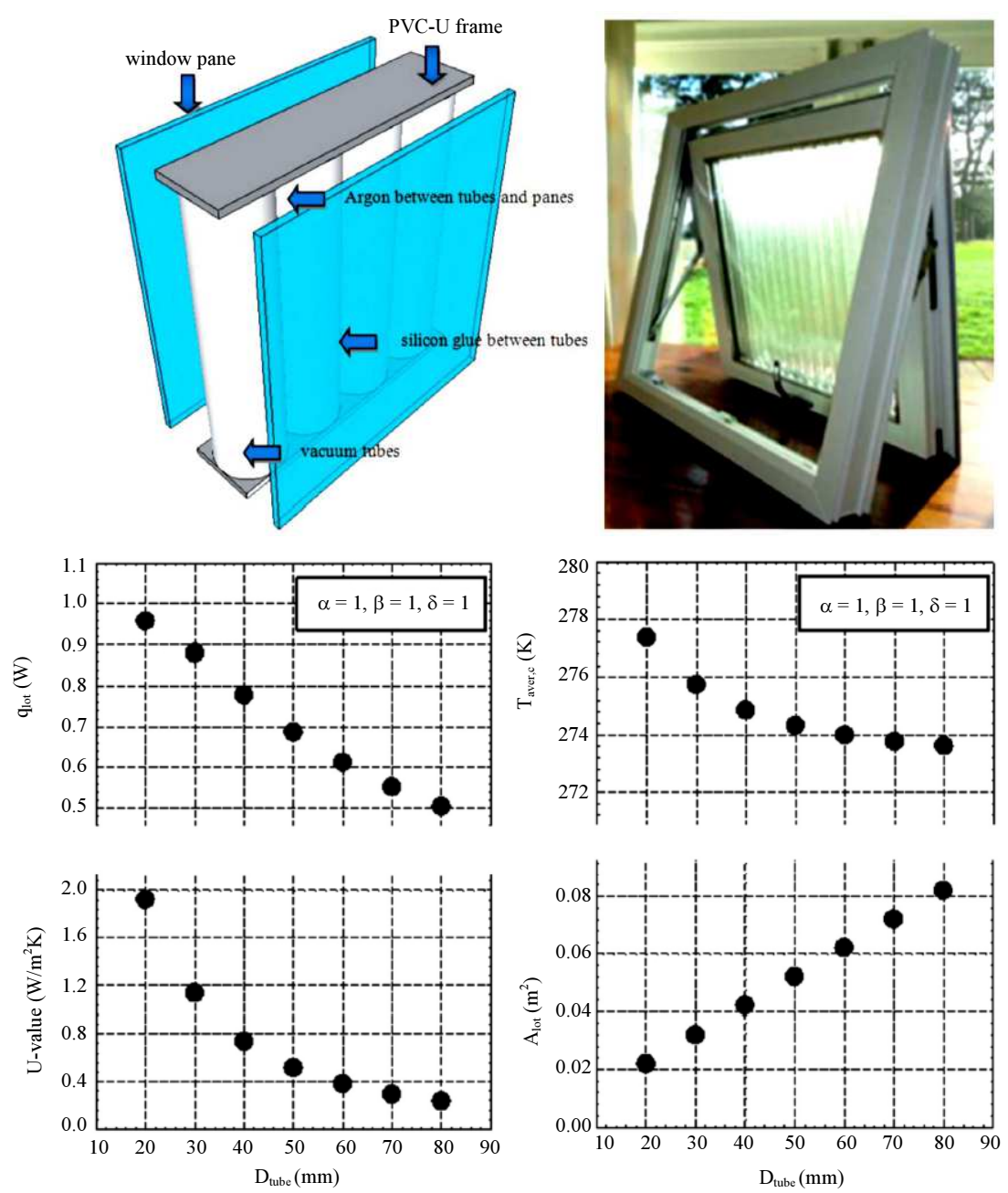

Fig. 7: U-value of vacuum tube window for different tube diameters (Cuce, 2017b)

\section{Solutions for Ventilation Systems}

Polycarbonate based waste heat recovery systems are found to be very promising to meet the ventilation demand of dwellings (Cuce et al., 2016c). These systems can also be integrated with semi transparent PV systems for clean energy generation (Cuce et al., 2013a). Thermodynamic performance assessment of such systems is already conducted in literature (Cuce et al., $2013 \mathrm{~b}$ ). The schematic of the heat recovery system and the test house are shown in Fig. 8.

Test results of the novel heat recovery technology are illustrated in Fig. 9. It is observed from the in-situ tests that polycarbonate based waste heat recovery unit is energy-efficient and cost-effective for low/zero carbon buildings. Average heat recovery effectiveness and COP of the system are found to be $88.6 \%$ and 4.47 , respectively. The heat recovery unit is also reasonable in terms of investment and payback time. The payback period is determined to be about 1.7 years. The system developed can be used in both summer and winter conditions without requiring any additional unit.

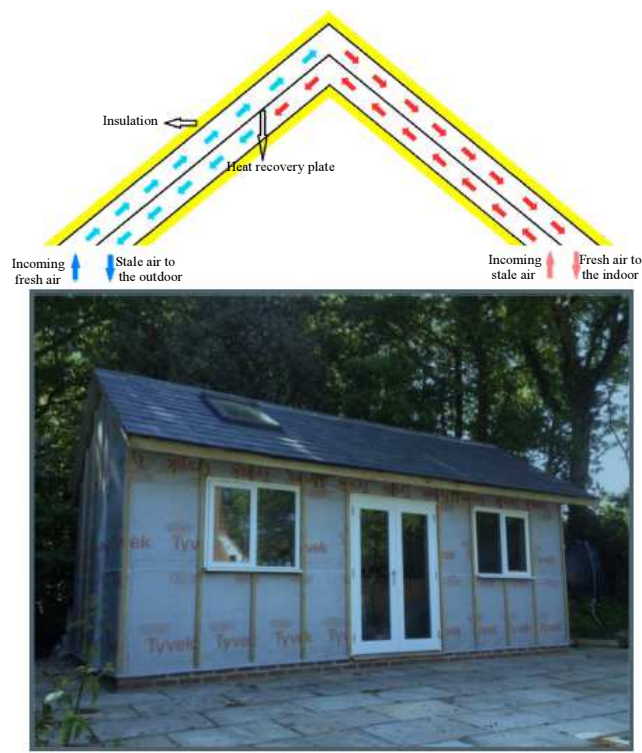

Fig. 8: Novel roof type heat recovery panel and the test house (Cuce et al., 2016) 

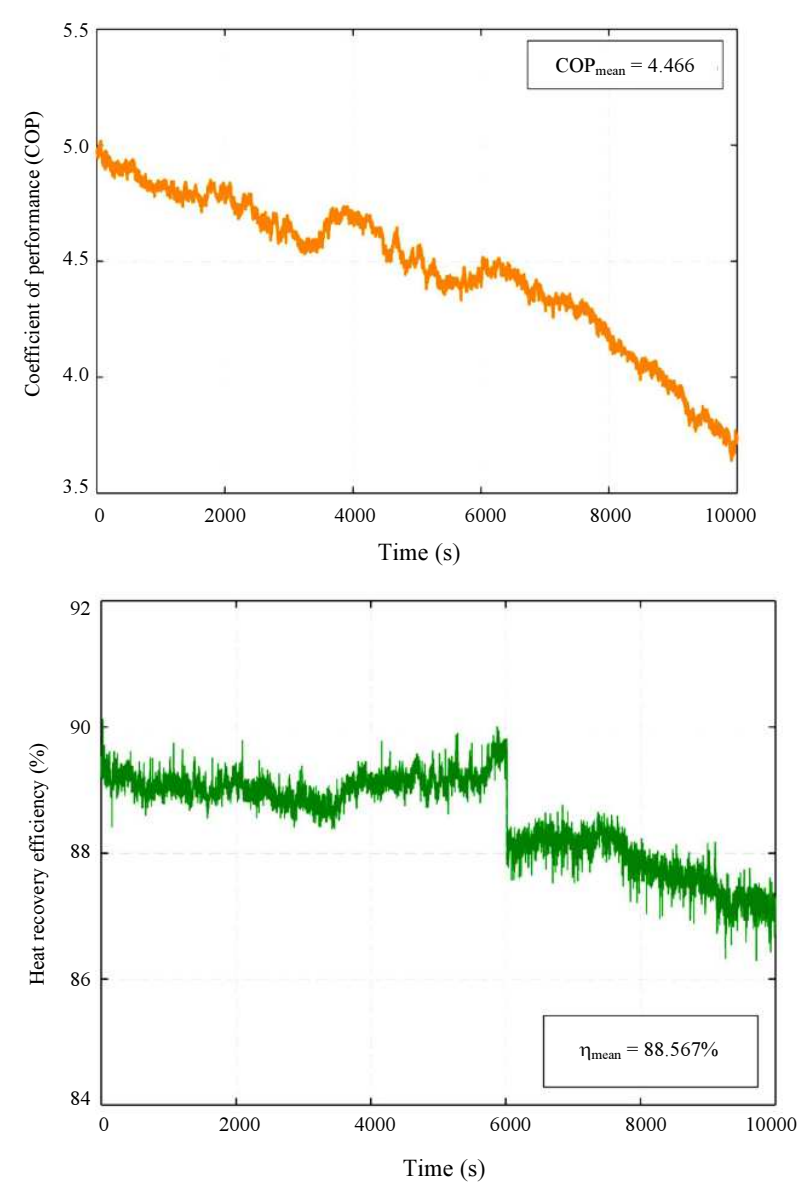

Fig. 9: Novel roof type heat recovery panel and the test house (Cuce et al., 2016)

\section{Conclusion}

In this research, smart, energy-efficient, low-cost and eco-friendly solutions are proposed for buildings toward a low carbon world. The solutions cover a wide range of aspects from building envelope elements to HVAC systems. Some characteristic results from the study can be listed as follows:

- Aerogel and vacuum insulation panels are ideal thermal superinsulation materials for external walls owing to their superior thermal resistance feature. Thermal conductivity of these materials is almost below $0.01 \mathrm{~W} / \mathrm{mK}$ in most cases. More than $90 \%$ of heat losses from building fabric can be reduced via aerogel and vacuum insulation panels. Current cost of thermal superinsulation materials is notably high compared to conventional insulation materials. However, remarkable cost reductions (below $£ 500.00$ by 2050) are predicted for the near future

- Vacuum glazing can be considered in extremely cold climatic conditions. U-value of a vacuum glazing unit with a tube diameter of $60 \mathrm{~mm}$ is below $0.40 \mathrm{~W} / \mathrm{m}^{2} \mathrm{~K}$, which is very promising
- Support pillars are of vital importance in vacuum glazing concept. Replacement of metallic support pillars with translucent aerogel can reduce the Uvalue from 1.20 to $0.67 \mathrm{~W} / \mathrm{m}^{2} \mathrm{~K}$

- Solar pond window is capable of providing high thermal regulation in building envelope. Although the entire thickness of the unit is notably higher than the other glazing concepts, low-cost and ecofriendly structure makes solar pond window special to be utilised in extremely hot climatic conditions.

- PV glazing is an attractive fenestration product. When a PV glazing is integrated with the concept of multilayer glazing, very promising U-value ranges can be achieved. Heat insulation solar glass can generate more than $90 \mathrm{~W}$ electricity from per $\mathrm{m}^{2}$ of cell area. The overall U-value of the unit is $1.10 \mathrm{~W} / \mathrm{m}^{2} \mathrm{~K}$, which is competitive with triple glazed systems

- Waste heat recovery technologies are in the centre of interest owing to their key role in mitigating ventilation oriented energy consumptions. Polycarbonate based waste heat recovery systems have an average COP above 4, which is very attractive. Heat recovery effectiveness of such systems is about $88 \%$

- It can be concluded that the solutions presented in this research have a great potential to reduce energy consumed in building sector

\section{Author's Contributions}

Erdem Cuce: Mentoring the research and revising/editing the body.

Pinar Mert Cuce: Preparation of the main draft following the collecting data and evaluating the findings.

\section{Ethics}

This article is original and contains unpublished material. The corresponding author confirms that all of the other authors have read and approved the manuscript and no ethical issues involved.

\section{References}

Besir, A.B. and E. Cuce, 2018. Green roofs and facades: A comprehensive review. Renewable Sustainable Energy Rev., 82: 915-939.

DOI: $10.1016 /$ j.rser.2017.09.106

Cuce, E. and P.M. Cuce, 2013a. Tilt angle optimization of building-integrated photovoltaics (BIPVs) for cooler operating temperatures. Proceedings of the MEGS IV Annual Conference, Public Engagement with Energy, Sept. 12-13, Loughborough, United Kingdom.

Cuce, P.M. and E. Cuce, 2013b. Passive cooling of building-integrated photovoltaics (BIPVs) for better electrical performance. Proceedings of the MEGS IV Annual Conference, Public Engagement with Energy, Sept. 12-13, Loughborough, United Kingdom. 
Cuce, E. and P.M. Cuce, 2016a. Buildings of future: Smart, low-cost and energy-efficient solutions. Proceedings of the 2nd International Conference on Industrial, Mechanical, Electrical and Chemical Engineering and Annual Conference on Industrial and System Engineering. Oct. 6-7, Yogyakarta, Indonesia.

Cuce, E. and P.M. Cuce, 2016b. The impact of internal aerogel retrofitting on the 313 thermal bridges of residential buildings: An experimental and statistical research. Energy Buildings, 116: 449-454. DOI: $10.1016 /$ j.enbuild.2016.01.033

Cuce, E. and P.M. Cuce, 2016c. Vacuum glazing for highly insulating windows: Recent developments and future prospects. Renewable Sustainable Energy Rev., 54: 1345-1357.

DOI: $10.1016 /$ j.rser.2015.10.134

Cuce, E. and S.B. Riffat, 2015a. Vacuum tube window technology for highly insulating building fabric: An experimental and numerical investigation. Vacuum, 111: 83-91. DOI: 10.1016/j.vacuum.2014.10.002

Cuce, E. and S.B. Riffat, 2015b. A state-of-the-art review on innovative glazing technologies. Renewable Sustainable Energy Rev., 41: 695-714. DOI: 10.1016/j.rser.2014.08.084

Cuce, E. and S.B. Riffat, 2015c. Aerogel-assisted support pillars for thermal performance enhancement of vacuum glazing: A CFD research for a commercial product. Arabian J. Science Eng., 40: 2233-2238. DOI: 10.1007/s 13369-015-1727-5

Cuce, E. and S.B. Riffat, 2016. A comprehensive assessment of sectoral energy consumption in the UK: past, present and future. Int. J. Low-Carbon Technologies, 11: 424-430. DOI: $10.1093 /$ ijlct/ctv013

Cuce, E. and S.B. Riffat, 2017. A smart building material for low/zero carbon applications: Heat insulation solar glass - Characteristic results from laboratory and in-situ tests. Int. J. Low-Carbon Technol., 12: 126-135.

Cuce, E., 2014. Development of innovative window and fabric technologies for low-carbon buildings. Ph.D. Thesis, The University of Nottingham.

Cuce, E., 2015. Toward thermal superinsulation technologies in buildings: Latest developments in glazing and building fabric. LAP Lambert Academic Publishing, Saarbrücken, Germany.

Cuce, E., 2016a. An overview of domestic energy consumption in the UK: past, present and future. Int. J. Ambient Energy, 37: 428-435. DOI: $10.1080 / 01430750.2014 .973120$

Cuce, E., 2016b. Toward multi-functional PV glazing technologies in low/zero carbon buildings: Heat insulation solar glass - Latest developments and future prospects. Renewable Sustainable Energy Rev., 60: 1286-1301.

DOI: $10.1016 /$ j.rser.2016.03.009
Cuce, E., 2017a. Role of airtightness in energy loss from windows: Experimental results from in-situ tests. Energy Buildings, 139: 449-455.

DOI: $10.1016 /$ j.enbuild.2017.01.027

Cuce, E., 2017b. Experimental and numerical investigation of a novel energy-efficient window technology for low-carbon buildings: Vacuum tube window. Indoor Built Environ., 26: 44-59.

DOI: $10.1177 / 1420326 \times 15599188$

Cuce, E., 2018. Accurate and reliable U-value assessment of argon-filled double glazed windows: A numerical and experimental investigation. Energy Buildings, 171: 100-106.

DOI: $10.1016 /$ j.enbuild.2018.04.036

Cuce, E., C.H. Young and S.B. Riffat, 2015a. Thermal insulation, power generation, lighting and energy saving performance of heat insulation solar glass as a curtain wall application in Taiwan: A comparative experimental study. Energy Conversion Management, 96: 31-38.

DOI: 10.1016/j.enconman.2015.02.062

Cuce, E., C.H. Young and S.B. Riffat, 2015b. Thermal performance investigation of heat insulation solar glass: A comparative experimental study. Energy Buildings, 86: 595-600.

DOI: 10.1016/j.enbuild.2014.10.063

Cuce, E., C.H. Young and S.B. Riffat, 2015c. Thermal insulation, power generation, lighting and energy saving performance of heat insulation solar glass as a curtain wall application in Taiwan: A comparative experimental study. Energy Conversion Management, 96: 31-38.

DOI: 10.1016/j.enconman.2015.02.062

Cuce, E., E.K. Oztekin and P.M. Cuce, 2018. Hybrid photovoltaic/thermal (HPV/T) systems: From theory to applications. Energy Res. J.

DOI: $10.3844 /$ erjsp. 2018

Cuce, E., C.H. Young and S.B. Riffat, 2016a. Performance investigation of heat insulation solar glass for low-carbon buildings. Energy Conversion Management, 88: 834-841.

Cuce, E., P.M. Cuce and C.H. Young, 2016b. Energy saving potential of heat insulation solar glass: Key results from laboratory and in-situ testing. Energy, 97: 369-380. DOI: 10.1016/j.energy.2015.12.134

Cuce, E., P.M. Cuce, C.J. Wood and S.B. Riffat, 2014a. Optimizing insulation thickness and analyzing environmental impacts of aerogel-based thermal superinsulation in buildings. Energy Buildings, 77: 28-39. DOI: 10.1016/j.enbuild.2014.03.034

Cuce, E., P.M. Cuce, C.J. Wood and S.B. Riffat, 2014b. Toward aerogel based thermal superinsulation in buildings: A comprehensive review. Renewable Sustainable Energy Rev., 34: 273-299. DOI: 10.1016/j.rser.2014.03.017 
Cuce, E., P.M. Cuce, C.J. Wood and S.B. Riffat, 2014c. Toward aerogel based thermal superinsulation in buildings: A comprehensive review. Renewable Sustainable Energy Reviews, 34: 273-299. DOI: 10.1016/j.rser.2014.03.017

Cuce, P.M. and E. Cuce, 2017. Toward cost-effective and energy-efficient heat recovery systems in buildings: Thermal performance monitoring. Energy, 137: 487-494. DOI: 10.1016/j.energy.2017.02.159

Cuce, P.M., E. Cuce and S.B. Riffat, 2013a. Theoretical investigation of solar powered heat recovery panels in buildings. Proceedings of the 12th International Conference on Sustainable Energy Technologies, Aug. 26-29, Hong Kong, China.

Cuce, P.M., E. Cuce and S.B. Riffat, 2013b. Second law analysis of solar powered heat recovery panels in buildings. Proceedings of the 12th International Conference on Sustainable Energy Technologies. Aug. 26-29, Hong Kong, China.

Cuce, P.M., E. Cuce and S.B. Riffat, 2016. A novel roof type heat recovery panel for low-carbon buildings: An experimental investigation. Energy Buildings, 113: 133-138. DOI: 10.1016/j.enbuild.2015.12.024

Cuce, P.M., E. Cuce, K.G. Bayraktar and S.B. Riffat, 2016c. In-situ thermal performance monitoring of a novel domestic heat recovery unit. Proceedings of the 15th International Conference on Sustainable Energy Technologies. Jul. 19-22, Singapore.

Daneshazarian, R., E. Cuce and P.M. Cuce, 2017. An overview of concentrating photovoltaic thermal (CPVT) collectors. Energy Res. J., 8: 11-21. DOI: 10.3844/erjsp.2017.11.21

Daneshazarian, R., E. Cuce, P.M. Cuce and F. Sher, 2018. Concentrating Photovoltaic Thermal (CPVT) collectors and systems: A comprehensive review. Renewable Sustainable Energy Reviews, 81: 473-492. DOI: 10.1016/j.rser.2017.08.013
Ding, Y., E. Cuce, S.B. Riffat and C. Lu, 2015. Investigation on the performance of air source heat pump system with new environment friendly refrigerants for a low carbon building. Proceedings of the 14th International Conference on Sustainable Energy Technologies. Aug. 25-27, Nottingham, United Kingdom.

Kalnæs, S.E. and B.P. Jelle, 2014. Vacuum insulation panel products: A state-of-the-art review and future research pathways. Applied Energy, 116: 355-375. DOI: $10.1016 /$ j.apenergy.2013.11.032

Moretti, E., F. Merli, C. Buratti and E. Cuce, 2017. Thermal and acoustic properties of aerogels: Preliminary investigation of the influence of granule size. Energy Procedia, 111: 472-480. DOI: 10.1016/j.egypro.2017.03.209

Oleskowicz-Popiel, C. and M. Sobczak, 2014. Effect of the roller blinds on heat losses through a doubleglazing window during heating season in Central Europe. Energy Buildings, 73: 48-58. DOI: $10.1016 /$ j.enbuild.2013.12.032

Pool, M., 2009. Insulation of a mixed use building with 7 storeys in Munich with VIP. Proceedings of the $9^{\text {th }}$ International Vacuum Insulation Symposium. Sept. 17-18, London, UK.

Riffat, S.B. and E. Cuce, 2012. Aerogel with its outstanding features and building applications. Proceedings of the 11th International Conference on Sustainable Energy Technologies. Sept. 2-5, Vancouver, Canada.

Young, C.H., S.B. Riffat and E. Cuce, 2015. High capacity energy efficiency solar glass. Proceedings of the $14^{\text {th }}$ International Conference on Sustainable Energy Technologies. Aug. 25-27, Nottingham, United Kingdom. 